\title{
Toughening mechanisms in core-shell rubber modified polycarbonate
}

\author{
D. S. Parker*, H-J. Sue†, J. Huang and A. F. Yee \\ Department of Materials Science \& Engineering, The University of Michigan, \\ Ann Arbor, MI 48109, USA
}

(Received 18 September 1989; accepted 6 December 1989)

\begin{abstract}
We have conducted a study of toughening mechanisms in rubber modified polycarbonate systems in order to evaluate the sequence of deformation events which improve fracture toughness. We conclude that cavitation of the rubber particles occurs first, followed by massive shear yielding of the matrix material. The size and shape of the deformation zone created in front of the crack is governed by the mechanical properties of the rubber particles and the stress state at the crack tip. The importance of using a variety of analytical techniques to characterize deformation mechanism is also illustrated.
\end{abstract}

(Keywords: toughening; fracture toughness; core-shell rubber; polycarbonate; rubber modification)

\section{INTRODUCTION}

As the use of polymers in structural applications increases, the fracture toughness of the polymer may become a decisive factor in material selection. Therefore, much work has been done to develop effective toughening methods for polymers. One method which has been successful in toughening brittle or notch sensitive polymers is rubber toughening ${ }^{1-15}$. Simply stated, rubber toughening involves the addition of elastomeric inclusions into a polymer matrix. Some years ago Yee et al. studied the yield and fracture behaviour of some polycarbonate blends ${ }^{13-15}$, including one $e^{14}$ which is similar to the materials studied in this paper. They concluded at that time that the impact modifier relieved the plane strain constraint ${ }^{14,15}$, thereby reducing the notch ${ }^{13,14}$ and rate sensitivity ${ }^{14,15}$ of the material. From scanning electron microscopy ${ }^{14,15}$ and tensile dilatometry studies ${ }^{15}$, they also concluded that shear yielding of the matrix was the main source of toughness ${ }^{14,15}$, though this conclusion would seem to be hardly surprising for a material as ductile as polycarbonate. In these studies the constraints imposed on the specimen were not very severe ${ }^{13-15}$. Even for notched specimens the notch tip radii were rather blunt ${ }^{14,15}$. Also, the plastic deformations other than those observable on the fracture surface were not studied. Yee et al. did not have any detailed knowledge of the sequence of deformation events and possible causal effects between them. Therefore, the respective roles of the impact modifier and the matrix and their adhesion to each other were not well understood. Several theories discuss the important deformation mechanisms which are operative in rubber toughened systems ${ }^{9-17}$. In systems which deform preferentially by shear yielding, the major toughening mechanisms are thought to be cavitation of the rubber particles and shear yielding of the matrix. Although the major deformation processes may be

\footnotetext{
* Present address: 3M Company, St Paul, MN 55144-1000, USA

$\dagger$ Present address: Polymer Center, Dow Chemical, USA, Freeport, TX 77541, USA

$\ddagger$ To whom correspondence should be addressed
}

defined, the sequence of events, i.e. whether cavitation occurs first followed by shear yielding or shear yielding occurs first followed by cavitation of the rubber particles, is still debated. A quantitative theory that successfully accounts for the contribution of various toughening mechanisms depends critically on knowledge of the sequence of events and their causal relationships.

Yee and Pearson ${ }^{9,10}$ investigated this point by conducting post mortem analysis on completely fractured specimens of rubber toughened epoxy. They concluded that cavitation of the rubber particles occurs first, and that this event relieves the triaxial tension and is then followed by enhanced shear yielding. However, some workers still assume that the rubber particles cavitate after the formation of shear bands ${ }^{8,18,19}$. Others do not explicitly specify the sequence $e^{6,20}$. It is apparent that a more definitive investigation is necessary.

In this paper we present evidence which clearly illustrates the sequence of cavitation and shear banding during the fracture of rubber toughened polycarbonate. We also discuss the importance of using a variety of analytical techniques to disclose toughening mechanisms and the sequence of events.

\section{EXPERIMENTAL}

Polycarbonate $(\mathrm{PC})\left(\operatorname{Lexan}^{\circledR} 141, M_{\mathrm{w}} \approx 26000\right.$, produced by General Electric) was used as a model matrix and was blended with 5, 10 and $15 \mathrm{wt} \%$ of two types of impact modifiers (IM) using a twin screw extruder. A smaller batch containing $3.3 \mathrm{wt} \%$ of the IMs was produced with a Brabender mixer. The IMs used were Acryloid ${ }^{\circledR}$ KM330 and KM653 (products of Rohm \& Haas). These are core-shell impact modifiers consisting of a glassy shell and a rubber core. The two IMs are quite different: KM330 consists of a polymethylmethacrylate (PMMA) shell and a polybutylacrylate core $\left(T_{\mathrm{g}} \approx-45^{\circ} \mathrm{C}\right)$ and KM653 has a PMMA shell and a polybutadiene core $\left(T_{\mathrm{g}} \approx-80^{\circ} \mathrm{C}\right)$. The PMMA shells of both IMs are miscible with $\mathbf{P C}^{21}$. The advantage of using Acryloid ${ }^{\circledR}$ impact modifiers is that with good dispersion, the particle 
size $(\mathrm{KM} 330, \approx 0.6 \mu \mathrm{m} ; \mathrm{KM} 653, \approx 0.2 \mu \mathrm{m})$ and shape are not influenced by the processing conditions. Also, because the properties of the two cores are different, we can investigate the influence of mechanical properties of the rubber particles on fracture toughness. The materials containing $3.3 \mathrm{wt} \%$ IM were compression moulded into $6 \mathrm{~mm}$ thick plates. The rest of the materials were injection moulded into plates and tensile specimens.

\section{FRACTURE TOUGHNESS}

The fracture toughness of the PC materials was determined using the $J$ integral analysis. The $J$ integral analysis, first proposed by $\mathrm{Rice}^{22}$, is a two-dimensional energy line integral that can be used to characterize the crack tip stress and strain field under both elastic and elasticplastic stress-strain conditions. A multiple specimen resistance curve method first developed by Landes and Begley ${ }^{23}$, and later adopted as the recommended procedure for metals by ASTM $^{24}$, was used to determine the critical $J$ value $\left(J_{1 \mathrm{c}}\right)$ for crack extension. The actual testing procedure is explained in the above references.

Sample preparation consisted of the following procedure. Three point bend (3PB) test specimens $11 \mathrm{~mm}$ thick were cut from injection moulded plates (actual specimen dimensions are shown in Figure 1). To produce reliable results the use of a proper notching technique is extremely important. However, since PC is extremely tough, the following procedure was adopted. The initial crack was produced by notching the specimen using a single point fly cutter (notch tip radius $=0.0254 \mathrm{~mm}$ ) to a depth of $5.6 \mathrm{~mm}$. The notch was then scored with a razor blade to a total depth of $6.4 \mathrm{~mm}$ (height/crack length, $a / w=0.5$ ), which acted as the initial starter crack. This notching/scoring procedure was performed because it is very difficult to produce a sharp starter crack in ductile materials. Also, immediately upon loading, the crack tip will be blunted by the nonlinear deformation which occurs at the crack tip. It is therefore assumed that the notching/scoring method produces sufficiently sharp cracks.

Tests were performed on a servo-hydraulic testing machine (Instron model 1331) at a displacement rate of

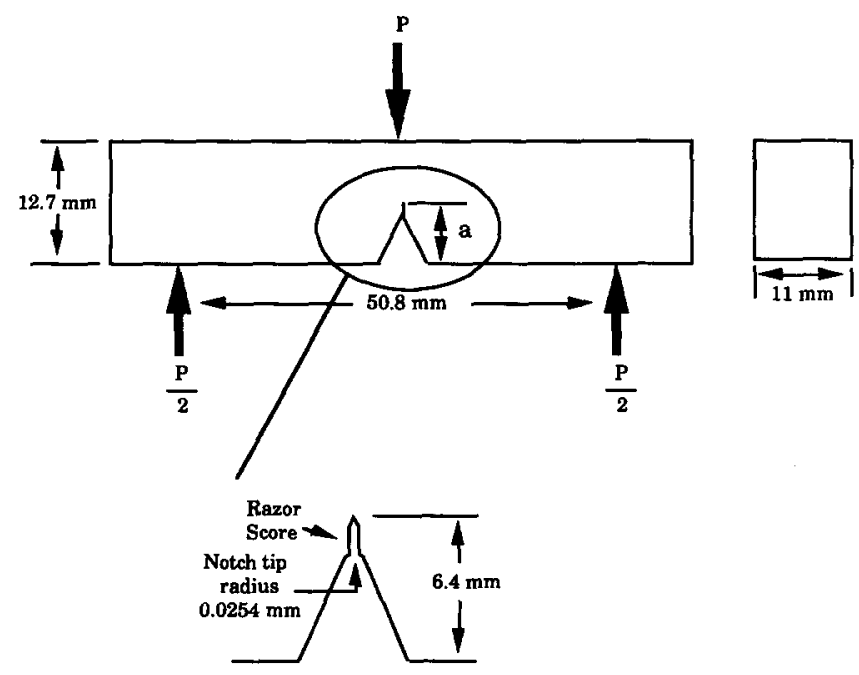

Figure 1 Schematic of the three-point bend test specimen used for determining the critical $J$ value for crack initiation $\left(J_{\mathrm{lc}}\right)$. A starter crack was produced by scoring the notch with the tip of a razor blade. The displacement rate used during testing was $2.54 \mathrm{~mm} \mathrm{~s}^{-1}$
$2.54 \mathrm{~mm} \mathrm{~s}^{-1}$. The three-point bend fixture used provided a span to specimen width ratio of $4: 1$. The load-deflection curve was recorded and monitored using a computer data collection program which allowed the potential energy (area below the load deflection diagram) to be calculated. After unloading, each specimen was immersed in liquid nitrogen and then broken so that the amount of crack extension $(\Delta a)$ could be measured from the fracture surface. Since the crack front is not a straight line an average value was taken. A $J$ value was then calculated using the following expression:

$$
J=\frac{2 U}{B(w-a)}
$$

where:

$$
\begin{aligned}
& U=\text { potential energy of the loaded body; } \\
& B=\text { thickness; } \\
& w=\text { height; } \\
& a=\text { crack length. }
\end{aligned}
$$

Next a plot of $J$ versus $\Delta a$ was constructed along with the blunting line $\left(J=2 \sigma_{y} \Delta a\right.$, where $\sigma_{y}=$ yield stress). The blunting line represents any nonlinear deformation that occurs at the crack tip which is not involved in the crack extension. The intersection of the straight blunting line and the $R$-curve determines the critical value $J_{\mathrm{Ic}}$ for crack initiation.

\section{TENSILE DILATOMETRY}

Tensile dilatometry is a relatively simple test that may provide a great deal of information for material characterization. In this test the basic mechanical properties of a material (Youngs modulus $(E)$, yield stress $\left(\sigma_{y}\right)$, yield strain $\left(\varepsilon_{y}\right)$ and Poisson's ratio $(v)$, etc.) in uniaxial tension can be determined. Under certain circumstances particular deformation mechanisms can also be inferred. Tensile dilatometry also provides insight regarding the mechanisms that may operate during fracture.

Injection moulded ASTM D638 type I tensile specimens were used in these tests. Five specimens of each material were tested under each set of conditions. The tests were made using a computer-aided servo-hydraulic testing machine under constant displacement control. Five specimens of each material were tested at displacement rates of 0.254 and $25.4 \mathrm{~mm} \mathrm{~s}^{-1}$, which produced initial strain rates of $\dot{\varepsilon}=2.5 \times 10^{-3}$ and $\dot{\varepsilon}=2.5 \times 10^{-1} \mathrm{~s}^{-1}$, respectively. Two extensometers were used to measure the longitudinal and transverse (width) strains respectively. The thickness strain was assumed to be identical to the width strain. The volume strain $\Delta V / V_{0}$ and the true stress were calculated using the formulae

$$
\begin{gathered}
\frac{\Delta V}{V_{0}}=\left(1+\varepsilon_{\mathrm{L}}\right)\left(1+\varepsilon_{\mathrm{T}}\right)^{2}-1 \\
\sigma=\frac{P}{W_{0} T_{0}\left(1-\varepsilon_{\mathrm{T}}\right)^{2}}
\end{gathered}
$$

where:

$\Delta V=$ change in volume;

$V_{0}=$ original volume;

$\varepsilon_{\mathrm{L}}, \varepsilon_{\mathrm{T}}=$ longitudinal and transverse engineering strains;

$W_{0}, T_{0}=$ original width and thickness;

$P=$ load;

$\sigma=$ true stress. 
In these tests the yield stress is defined as the maximum true stress value. Although strain data were collected past the yield point, they were not used for analysis because accurate strain measurements cannot be taken once a neck has formed. The strain rates reported are based on the average strain rate recorded within the initial 1-2\% strain region.

\section{MICROSCOPY}

Analysis of the fracture surfaces was performed using a Hitachi S-520 scanning electron microscope (SEM). However, SEM analysis by itself has limited value in determining the deformation mechanisms except in extremely brittle materials where surface energy dominates. To investigate these mechanisms and the sequence of events, in all but the most brittle materials, subsurface analysis must be used. The most ideal specimen for subsurface analysis is one which contains a crack with a mature plastic zone at its tip. One method which has been used to produce a specimen of this type is a double notch four point bend specimen $(\mathrm{DN}-4 \mathrm{~PB})^{25-27}$. This method involves loading a specimen which contains two nearly identical cracks in a four point bend geometry. One of the cracks will reach the critical state first and propagate, thus capturing a subcritically developed process zone at the tip of the remaining crack. This method was used to investigate fast fractures.

The DN-4PB specimens $\left(63.5 \times 12.7 \times 6.55 \mathrm{~mm}^{3}\right)$ (PC +3.3 wt $\%$ KM653) were cut from compressionmoulded plates. The samples were pre-notched with a jeweller's saw and pre-cracked using a liquid nitrogen chilled fresh razor blade, which was used to wedge open a crack by lightly tapping it with a hammer. These specimens were tested at room temperature using a screw driven testing machine at a crosshead speed of $8.47 \mathrm{~mm} \mathrm{~s}^{-1}$. Figure 2 illustrates the loading geometry for the DN-4PB sample. After testing, samples were taken perpendicular to the fracture surface for transmission electron microscopy (TEM). TEM samples were prepared by staining the rubber particles for $48 \mathrm{~h}$ using a $2 \% \mathrm{OsO}_{4}$ aqueous solution to produce contrast between the particles and the PC matrix. The samples were then sectioned, at room temperature, using an ultra-microtome. The $50 \mathrm{~nm}$ thick sections were observed in a Philips 400 TEM.

The DN-4PB specimen is best suited for more brittle materials where cracks propagate unstably and for high deformation rate testing. In our $J$ integral study all of the materials exhibited stable crack propagation. Therefore, specimens for subsurface analysis with optical microscopy were produced by taking identical specimens to those used for determining the $J_{\mathrm{Ic}}$ values and loading them to their respective critical $J$ values. The samples were then immediately unloaded, thus preserving a matured process zone in front of the crack tip. The advantages of this approach are that it eliminates the requirement of producing two nearly identical cracks in the specimen and the strain rate at the crack tip can be maintained constant throughout all of the tests.

A petrographic thin section technique ${ }^{28}$ was used to produce sections perpendicular to the crack tip (Figure 3 ) in the plane strain region. The thin sections were then examined by optical microscopy (OM) using a Nikon Microphot optical microscope with transmitted light and crossed polarizers.

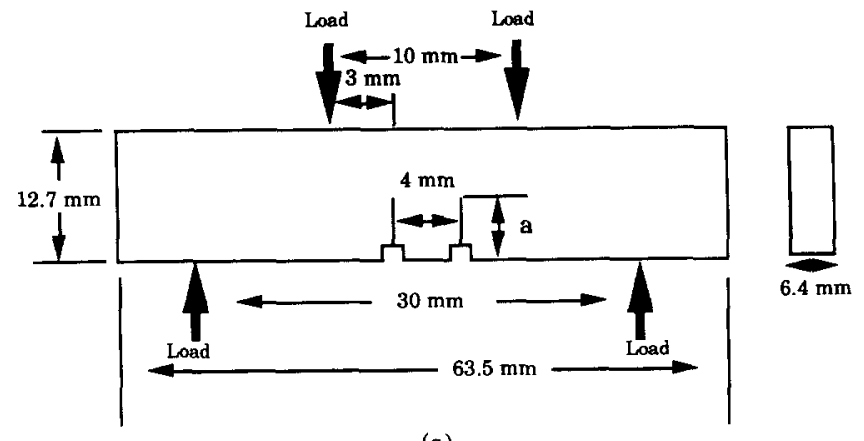

(a)

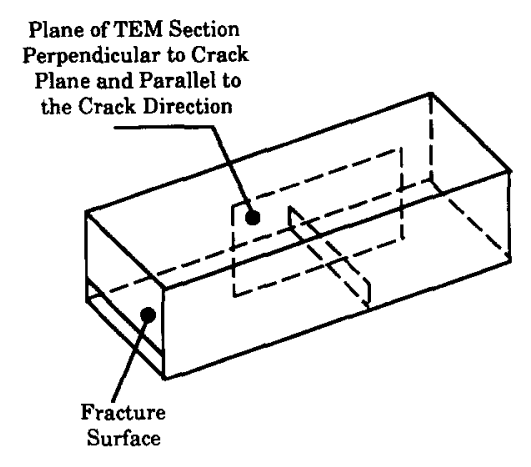

(b)

Figure 2 (a) Schematic of the DN-4PB test specimen used to evaluate fast fracture. (b) Orientation of the plane from which a TEM sample was removed

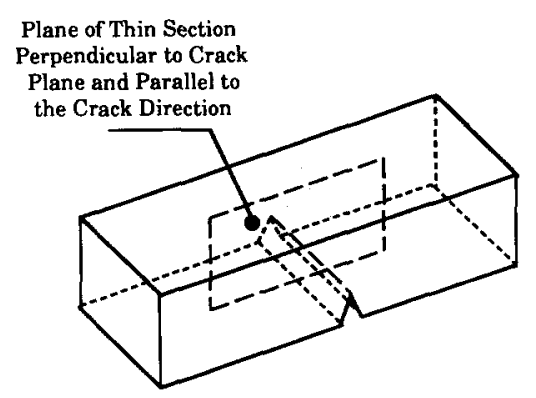

Figure 3 Orientation of petrographic thin section used to view the plastic zone in the plane strain region, which was used for evaluating stable fracture for the $J$ integral testing configuration

In the critical $J$ tests, additional subsurface analysis was also performed on PC modified with KM653 by using a standard microtomy technique and TEM, as described in the $\mathrm{DN}-4 \mathrm{~PB}$ technique.

\section{RESULTS AND DISCUSSION}

\section{Fracture toughness measurement}

The $J_{\text {Ic }}$ values for all of the materials studied are shown in Figure 4. Clearly these submicrometre IMs are effective in toughening PC. Both types of IM produced very similar $J_{\text {Ic }}$ values for PC at 5 and $10 \mathrm{wt} \%$ additions. At an IM concentration of $15 \mathrm{wt} \%$ the $J_{\mathrm{Ic}}$ values decreased. To explain these observations SEM, TEM, OM and volume dilatation analysis were performed. 


\section{SEM of fracture surfaces}

Figures 5-7 are SEM micrographs of the fracture surface of the PC and the six specimens modified with IMs. The PC fracture surface indicates failure by a craze fibril breakdown process ${ }^{29}$. The fracture surface of the modified resins show signs of voiding and ductile tearing. These features are more pronounced in the specimens using KM 330 IMs. Specimens with $15 \mathrm{wt} \%$ IM additions show a great deal of void growth and ligament tearing, which may explain the decrease in the fracture toughness. It is possible to explain the dependences of the $J_{\mathrm{Ic}}$ on the IM content by the following qualitative arguments. We consider the interactions between the IM particles. At very small IM volume fractions, the interactions between the inclusions do not become significant until very large plastic strains have been reached. As the IM volume fraction is increased, the inclusions will begin to interact after moderate amounts of plastic strain. With further deformation the diameter of the ligaments between the inclusions are reduced even more by hole growth, which reduces their load carrying capacity (Figure 8 ). Consequently, the critical $J$-value for crack initiation is reduced. These observations will be further supported by subsurface analysis presented within the section on optical microscopy results.

An SEM micrograph of the fast fracture surface of the DN-4PB specimens is shown in Figure 9. Under fast

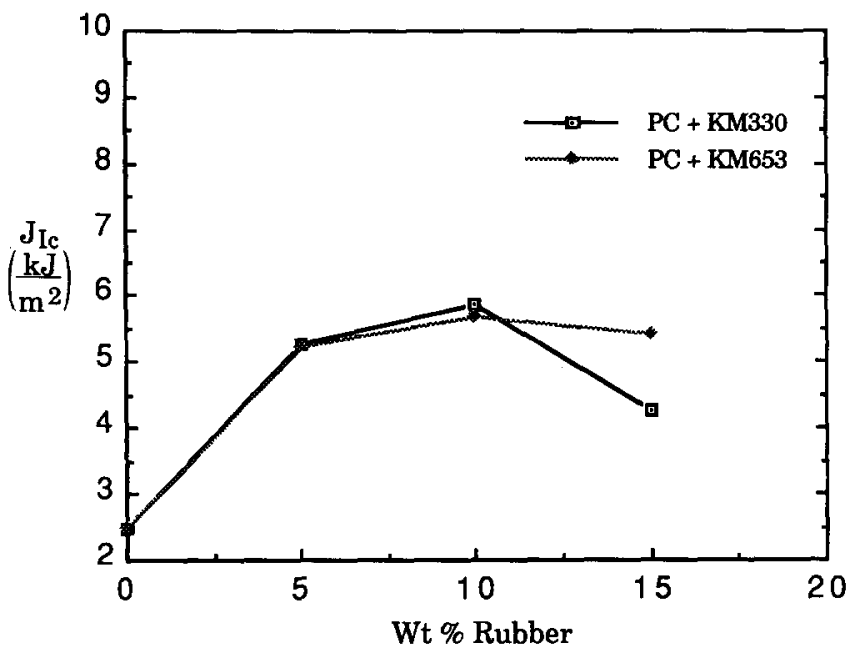

Figure $4 J_{\mathrm{Ic}}$ versus IM content for PC compounded with KM330 and KM635. All tests were conducted at room temperature at a displacement rate of $2.54 \mathrm{~mm} \mathrm{~s}^{-1}$ fracture conditions the surface shows limited plastic flow and the holes which form are close to the initial rubber particles in size. These results give the appearance that during fast fracture the rubber particles do not cavitate but only debond from the PC matrix. Yet, by conducting subsurface analysis using the TEM, the rubber particles are observed to be cavitated in a narrow region away from the fracture surface (Figure 10). These observations may imply that rubber cavitation by itself is not sufficient to induce shear yielding. In fast fracture, the yield stress is raised by the high strain rate and the cavitation may have occurred prematurely for such rates.

Clearly the SEM does provide some insight into the failure mechanisms; however, it does not allow one to analyse the energy absorbing mechanisms and the sequence of events or whether or not the two different IMs are behaving similarly. To provide answers to these questions, additional analysis using tensile dilatometry and subsurface microscopy techniques is attempted.

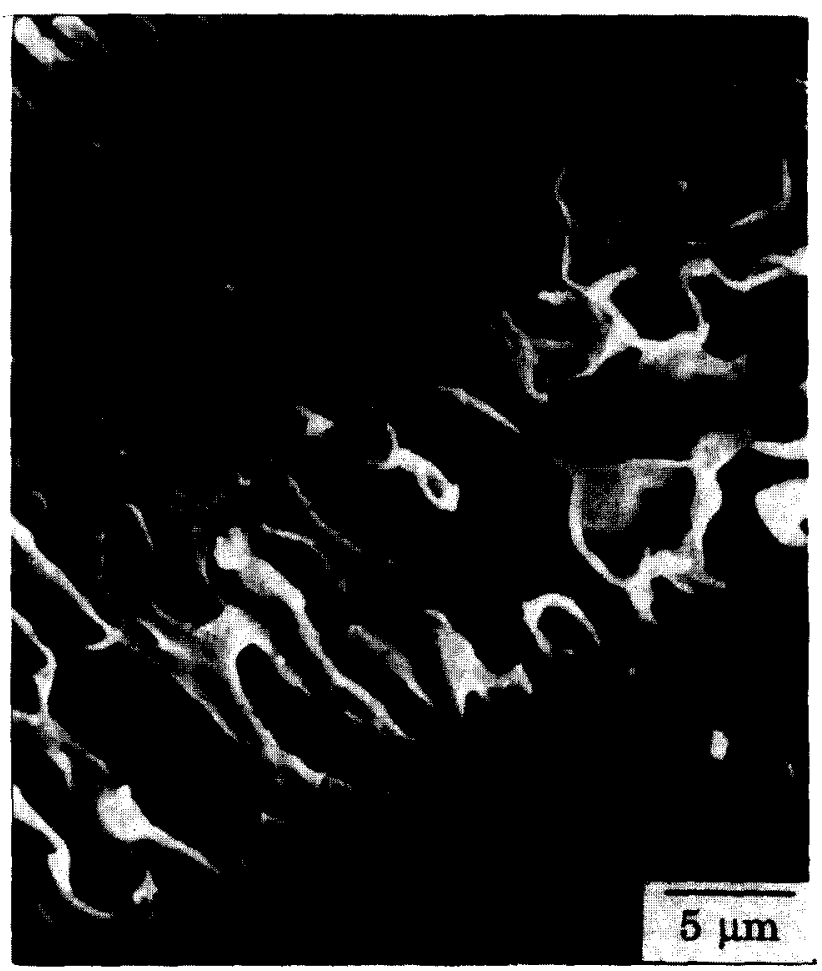

Figure 5 SEM photomicrograph of PC neat resin fracture surface of a $J$ integral test specimen
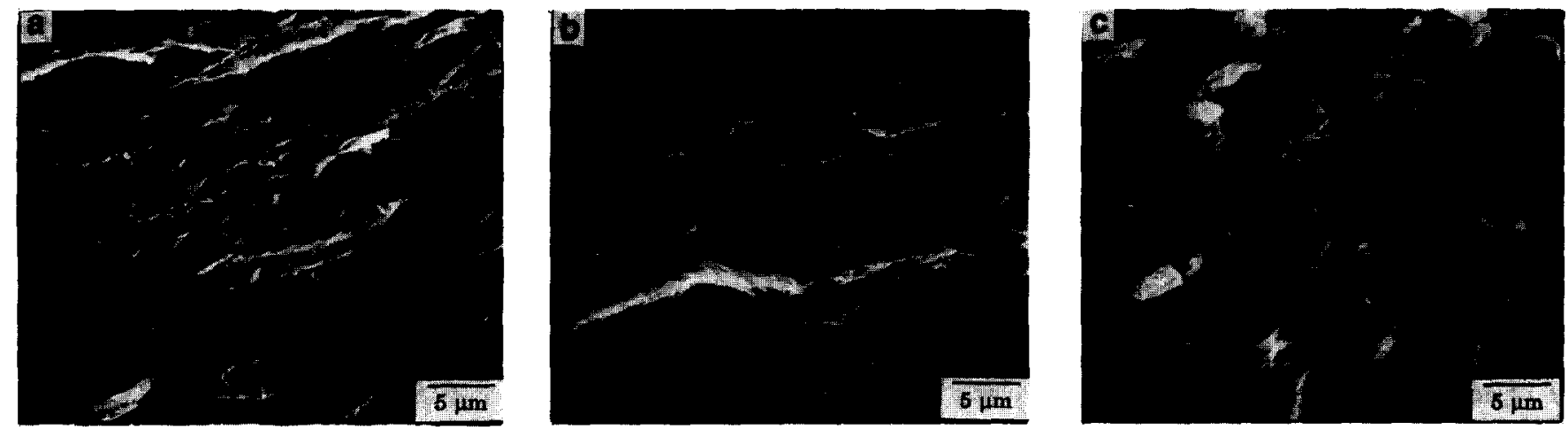

Figure 6 SEM photomicrographs of the fracture surface of $J$ integral test specimens for PC modified with KM330: (a) $5 \mathrm{wt} \%$; (b) $10 \mathrm{wt} \%$; (c) $15 \mathrm{wt} \%$ 

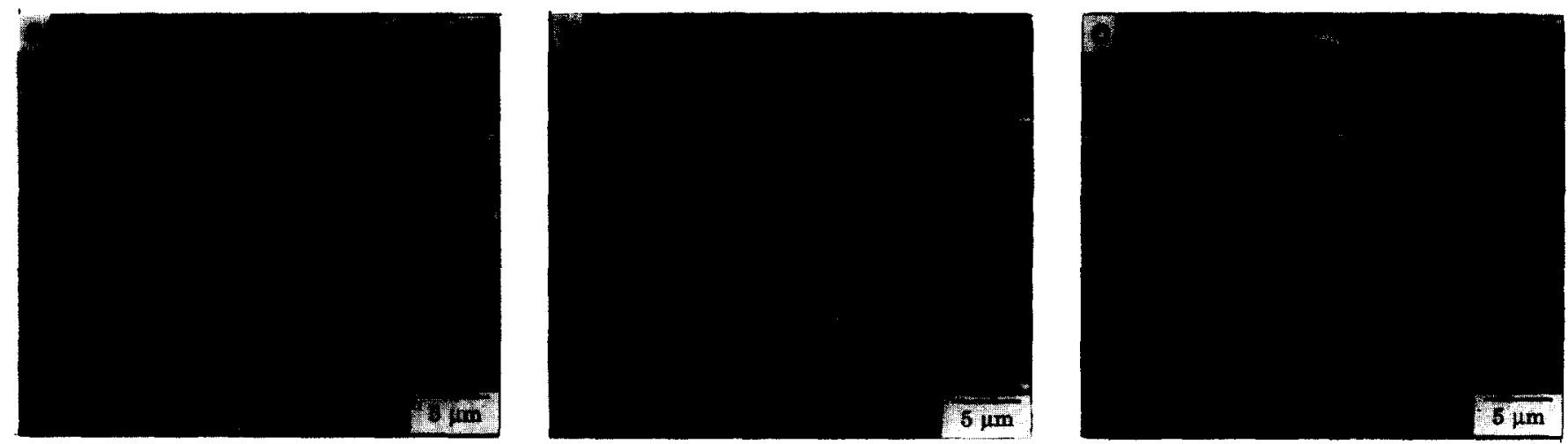

Figure 7 SEM photomicrographs of the fracture surface of $J$ integral test specimens for PC modified with KM653: (a) $5 \mathrm{wt} \% ;$ (b) $10 \mathrm{wt} \%$; (c) $15 \mathrm{wt} \%$
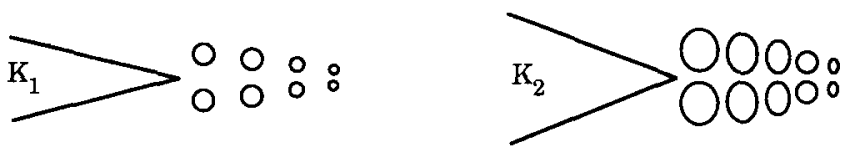

Figure 8 A schematic of the crack tip at two different $K$ values (each greater than the critical $K$ value for cavitation, $K_{2}>K_{1}>K$ ), illustrating that as the holes grow larger the ligaments between the holes are reduced, which lowers the load carrying capacity of the ligaments

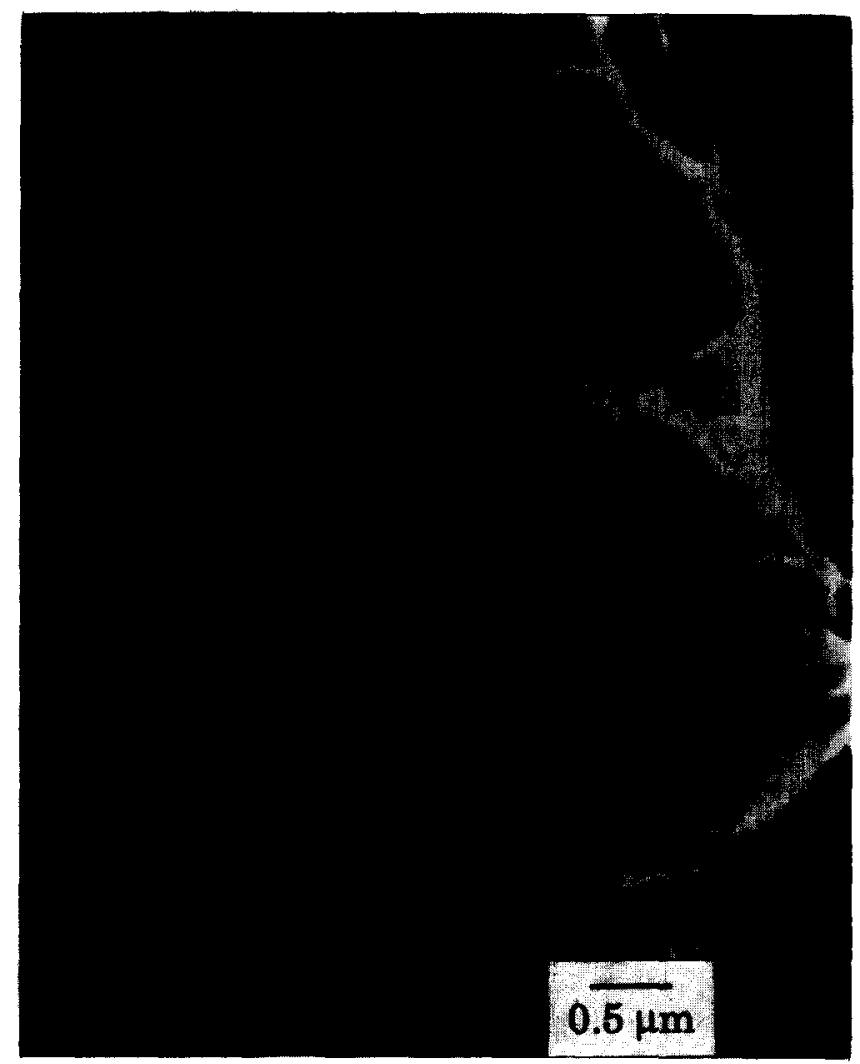

Figure 9 SEM photomicrograph of the fracture surface of the DN-4PB fast fracture specimen (PC $+3.3 \mathrm{wt} \% \mathrm{KM} 653)$

\section{Tensile dilatometry results}

Tensile dilatometry has been used by many investigators to evaluate the types of deformation mechanisms which operate during failure ${ }^{9-11,19}$. It is assumed that deformations associated with an increase in volume such as voiding or crazing are manifested by an increase in the volume strain. However, if both voiding and crazing occur simultaneously, it is impossible to separate their

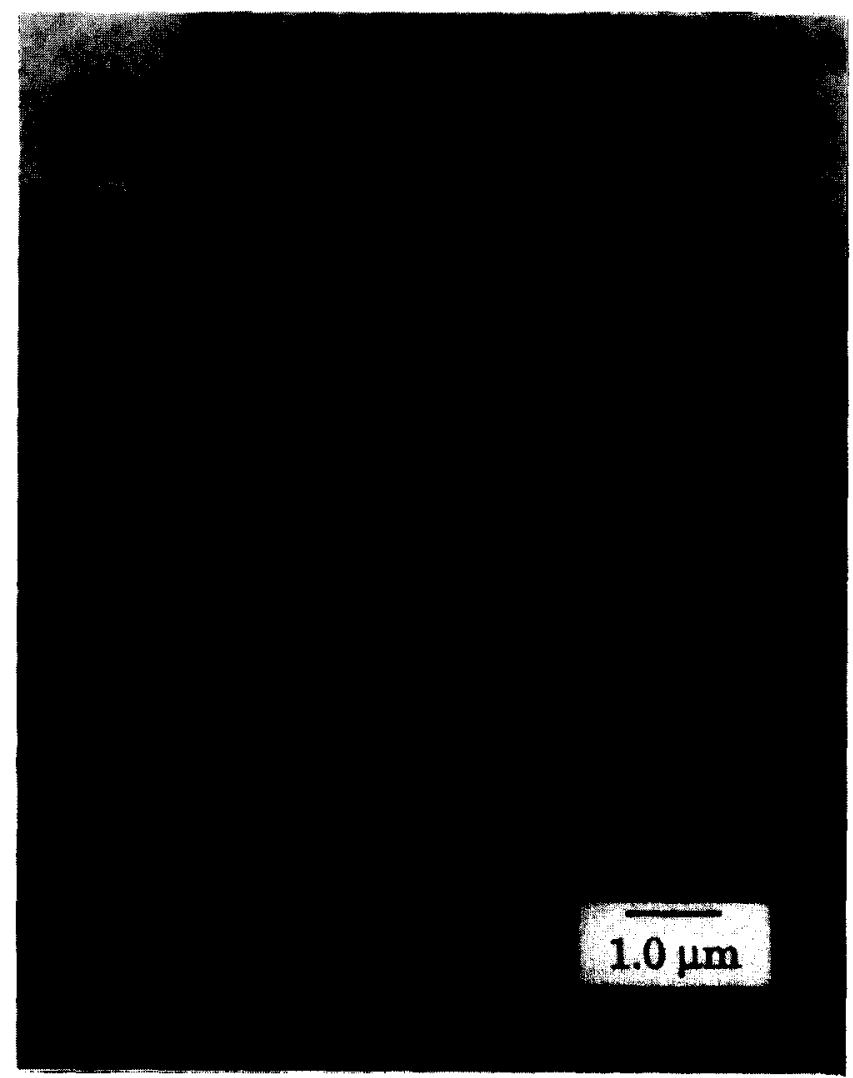

Figure 10 TEM photomicrograph of the $\mathrm{DN}-4 \mathrm{~PB}$ fast fracture specimen (PC+3.3 wt \% KM653) taken just below the fracture surface

respective contributions to volume strain. When shear yielding occurs, a decrease in the volume strain rate would be apparent since plastic deformation occurs at approximately constant volume. The materials in this study were subjected to this test at several strain rates. For brevity, only the tensile dilatometry results of PC modified with $10 \mathrm{wt} \%$ IM are shown (Figure 11). (These results represent a typical response observed for all of the materials tested.) In Figure $11 a$ the initial linear increase in the volume strain is due to a Poisson ratio effect. In this region all of the volume strain curves are similar. The material with $10 \mathrm{wt} \%$ KM653 does not show a significant increase in the volume strain over the pure resin. For $\mathrm{PC}+\mathrm{KM} 330$, the total volume strain is larger than the other materials at larger longitudinal strains. At the higher strain rate (Figure 11b), the total volume strain has increased over that at the slower rate, probably because the yield stress has now been raised 

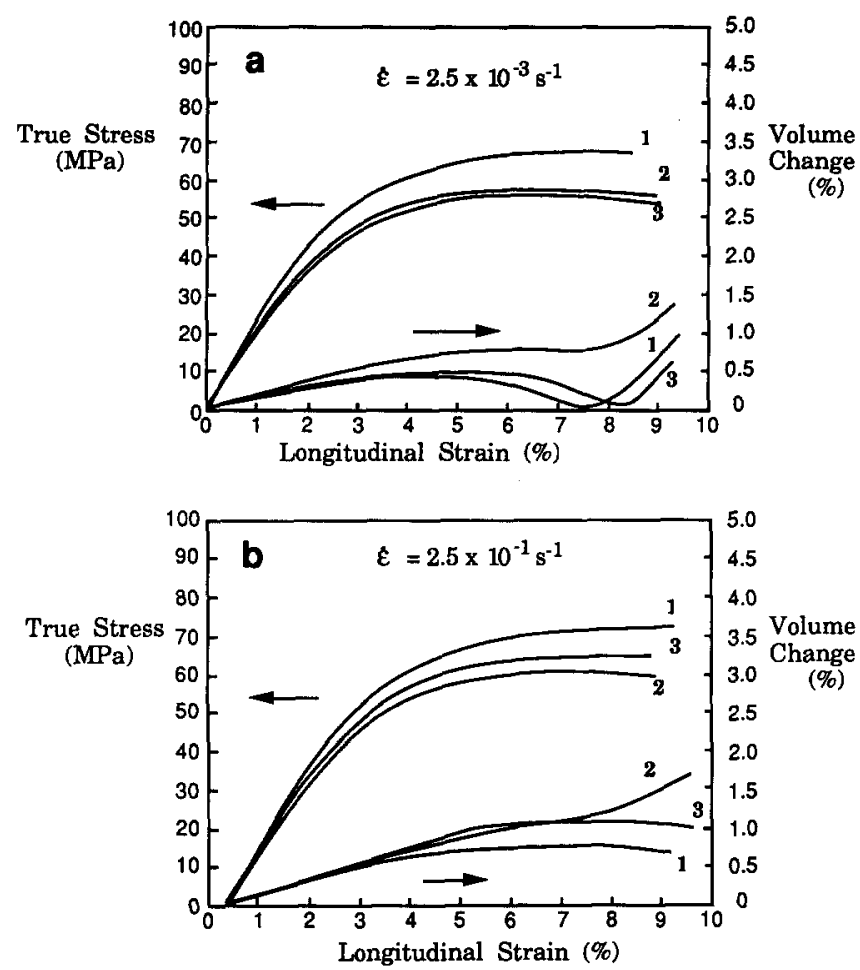

Figure 11 Dilatation and stress versus longitudinal strain for pure PC (curve 1), PC $+10 \mathrm{wt} \% \mathrm{KM} 330$ (curve 2) and $\mathrm{PC}+10 \mathrm{wt} \% \mathrm{KM} 653$ (curve 3) at: (a) $0.254 \mathrm{~mm} \mathrm{~s}^{-1}$; (b) $25.4 \mathrm{~mm} \mathrm{~s}^{-1}$

and shear yielding has therefore been delayed. This phenomenon was first observed by Yee and Pearson ${ }^{9}$.

Based on traditional interpretations, these results would indicate that the rubber additions have increased the volume strain due to cavitation of the rubber or interfacial failure. These results also suggest that at higher strain rates the two IMs behave similarly. In the next section we demonstrate through optical microscopy results that the two IMs behave quite differently and that, in fact, they would not be expected to produce similar responses during tensile dilatometry testing.

We conclude that volume dilatation tests for ductile materials do not provide sufficient details for understanding the deformation mechanisms that are enhanced by adding rubber to the matrix. This -conclusion is reached for the following reasons. First, PC at room temperature is very ductile and can easily deform by shear; at low strain rates the addition of rubber merely enhanced shear yielding. Second, under unidirectional tensile test conditions where there is no notch or crack present the hydrostatic stress will be lower and more homogeneously distributed than that in front of a crack tip. These factors suggest that caution must be exercised in using tensile dilatometry results to infer fracture mechanisms in the presence of a crack. When evaluating ductile materials volume dilatation results at low strain rates may be especially misleading or provide little insight into the deformation mechanisms.

\section{Optical microscopy}

By producing petrographic thin sections as described earlier, a plane containing the plastic zone oriented perpendicular to the crack growth direction can be viewed. In this case, because the crack has not propagated completely through the specimen, the sequence of deformation mechanisms can be determined. Figures $12 a-g$ are sections $\approx 100 \mu \mathrm{m}$ thick. The bulk PC sample (Figure
$12 a$ ) indicates that small crazes form in front of the crack tip and the process zone is very small. Figures $12 b-d$ are thin sections of PC with 5, 10 and 15 wt\% KM330 IM additions, respectively. Two distinct regions are visible in front of the crack tip. First, there is a large circular zone that extends out around the crack tip. Second, contained within the circular zone is a very dark elliptical zone. Both zones contain cavitated particles. The contrast in intensity is due to the differences in the concentration and the extent of cavitation of the rubber particles as well as the amount of shear deformation within the two zones. When the rubber particles cavitate and the holes enlarge, light scattering will increase. As the matrix undergoes shear yielding the refractive index will change, which contributes further to light scattering. The outer circular zone contains rubber particles that have cavitated due to the hydrostatic tension. To accommodate the cavitational strain of the rubber particles, it is clear that the surrounding matrix must also expand by a shear process. However, no birefringence is observed in this zone. This indicates that the strain in the matrix is largely elastic or anelastic in nature. Most of the dark elliptical zone is birefringent when viewed between crossed polarizers. This birefringent part of the dark elliptical zone is a region that has undergone plastic shear deformation and contains intensely cavitated rubber particles. The two zones will be referred to as follows: the circular zone is called process zone I and the dark elliptical zone is called the process zone II. We note that the zone I is observable only if the section is sufficiently thick. This is due to the low concentration of scattering centres in this zone.

Before the formation of a crack tip plastic zone the main principal stress and the mean stress both have their maximum values at the crack tip. These stresses decay with increasing distance away from the crack tip, and must be lower at points in process zone I than in process zone II. Therefore, the fact that cavitations are observed in zone $I$ indicates that this process must occur first during loading, followed by the formation of shear bands. The sequence of events is clearly one where the formation of zone I must precede zone II, as illustrated in Figure 13.

The crack tip deformation zone for PC modified with KM653 is quite different than that for the KM 330 series (Figures $12 e$ and $g$ ). In this case we only observe a single process zone. There are no signs of a process zone I which envelopes the plastic zone. This is not because KM653 does not cavitate but because KM653 apparently requires a higher critical hydrostatic stress for cavitation. Therefore, when KM653 does cavitate it does so at a larger applied load. Immediately after cavitation the resulting stress state is such that locally the PC matrix can form shear bands ${ }^{30}$. In this case the process zone and the cavitation zone overlap and no cavitation zone is observed.

To illustrate the fact that KM653 does indeed cavitate, a series of TEM photomicrographs of an $\mathrm{OsO}_{4}$ stained microtomed section of PC $+3.3 \mathrm{wt} \% \mathrm{KM} 653$ taken near the arrested crack tip (from a DN-4PB specimen) is shown in Figure 14. Figure 14a, which encompasses a relatively large field of view, shows cavitation and shearing of the rubber particles. Directly in front of the crack tip the rubber particles are highly elongated $(\approx 400 \%$ elongation). This is shown more clearly in Figure 14b. Further ahead of the crack tip (Figure 14c) 
Core-shell rubber modified polycarbonate: D. S. Parker et al.
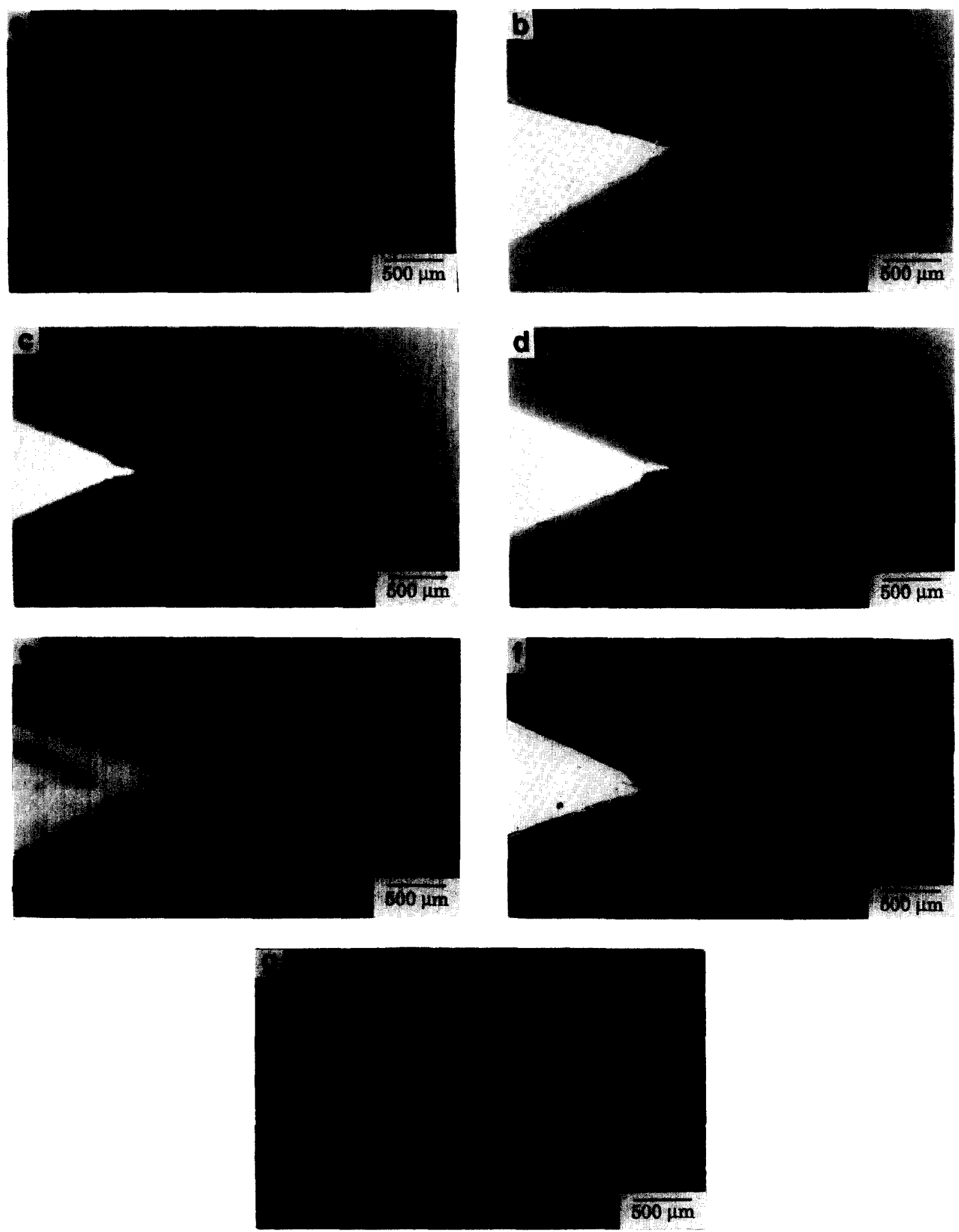

Figure 12 Petrographic thin sections $(100 \mu \mathrm{m}$ thick) of the matured deformation zone in front of a crack tip taken perpendicular to the crack plane ( $J$ integral configuration). These samples were produced by loading each specimen to their respective $J_{\text {Ic }}$ value. (a) PC pure resin; (b) PC $+5 \mathrm{wt} \%$ KM330; (c) PC + $10 w t \%$ KM330; (d) PC + $15 w t \%$ KM330; (e) PC + 5 wt $\%$ KM653; (f) PC $+10 w t \% \mathrm{KM} 653$; (g) PC $+15 w t \% \mathrm{KM} 653$

the particles are merely cavitated with little distortion. The approximately spherical shape of the cavities suggests that very little localized shearing has occurred. Some distortion of the particles is inevitable due to the microtoming. This effect can be assessed by comparing Figure $14 \mathrm{c}$ with Figure $14 d$, which is from a region with no cavitation and little deformation $(160 \mu \mathrm{m}$ ahead of the crack tip). In Figure 14e, the subsurface zone behind the crack tip is shown. Near the fracture surface the rubber particles are greatly elongated and reflect the very large plastic strain in the surrounding matrix. The shape of the particles and the absence of cavities in them indicate that, with increasing plastic strain as the fracture surface is approached, the cavities are gradually closed up by the large shear deformation. This is the reason why, in the optical micrographs, the region adjacent to the 


\section{Rubber Cavitation}

\section{Shear Yielding}

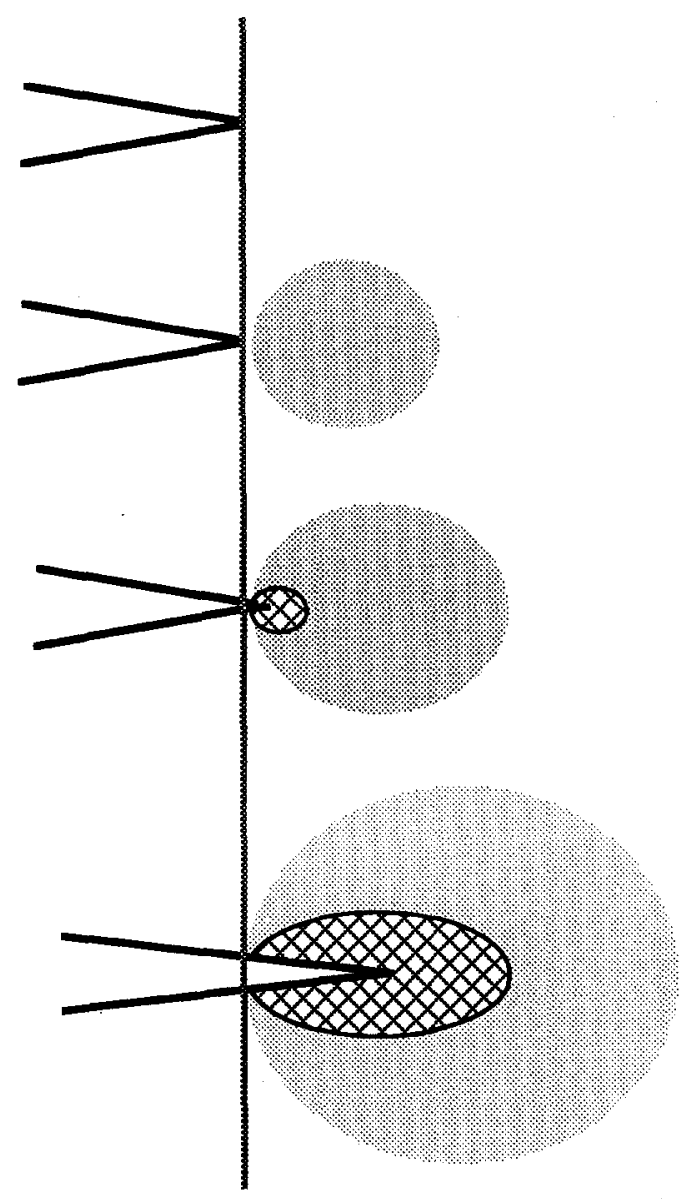

(a)

(b)

(c)

Figure 13 Sequence involved in the development of the deformation zone in front of the crack tip in rubber modified PC. (a) Initial crack tip. (b) Loading causes the rubber particles to cavitate forming a cavitation zone. (c) Once the triaxial stress state is relieved an initial shear yielded process zone is created. (d) A matured deformation zone is formed followed by crack propagation

fracture surface does not scatter light since the cavities are collapsed. The plastic shear deformation causes this zone to be highly birefringent. If one were to observe this fracture surface using SEM, at the proper viewing angle one would observe the spherical rubber particles shaded by extensive plastic deformation of the matrix. The role played by the rubber particle in inducing the sequence of events observed by the subsurface analysis would probably be completely missed. These micrographs support our earlier conclusion that cavitation of the rubber particles occurs first (albeit accompanied by elastic and plastic dilatation of the surrounding matrix) and is followed by enhanced localized shearing. For PC modified with KM653 the two process zones occupy approximately the same spatial region.

The TEM analysis also indicates that the interfacial adhesive strength between the IM particles and PC is higher than the cavitation resistance of the rubber. Therefore, cavitation rather than debonding of the rubber particles from the matrix occurs.

When the petrographic thin sections are reduced to $20 \mu \mathrm{m}$ in thickness, the size of process zone II can be clearly determined. Note that at this thickness process zone I is no longer visible in the KM330 series because there are too few scattering centres. The process zone II of KM330 and KM653 (Figures $15 b-g$ ) are similar in shape, but KM330 produces a slightly wider process zone II (Table 1) than KM653. Since the two IMs have different cavitation resistances, the stress and strain gradients in front of the crack tip must be different. This may be the origin of the differences observed in the shape of process zone II. However, we do not currently have a quantitative explanation of these observations, in part because we do not have a precise measure of the difference in cavitation resistances.

When comparing the process zones of the modified and unmodified materials, we conclude that the reduction of the hydrostatic stress in front of the crack tip (through cavitation of the rubber particles) significantly influences the ability of the material to shear yield. Although we have demonstrated that cavitation and shearing processes occur sequentially, they are coupled to each other. This effectively prevents one from separating the contribution of each mechanism to the improvement in fracture toughness. However, we can gain insight regarding which mechanism is the primary source of energy absorpton by comparing the relative size of the process zones observed using each IM. Process zones II of PC modified with KM330 and KM653 are similar in size (Table 1). In PC modified with KM330, process zone $I$ is much larger than process zone II (Figures 12b-d). In PC modified with KM653, process zones I and II can be considered to be identical in size (Figures $12 e-g$ ). Therefore, the volume of material containing cavities is much larger when PC is modified with $\mathrm{KM} 330$ than with $\mathrm{KM} 653$. Though $J_{\text {Ic }}$ cannot be correlated directly with the process zone size (since it comprises the starter crack arrest zone, the initiation zone and the final arrest zone), if the process of cavitation is a major source of energy absorption, the fracture toughness of PC modified with KM330 should be much larger than that found for PC+KM653. Yet, in both systems (with $<15 \mathrm{wt} \%$ IM), the fracture toughnesses are nearly the same. Therefore, we conclude that while cavitation of the rubber particles does absorb energy, the enhanced plastic deformation of the matrix is the major energy absorbing mechanism. This is not to say that cavitation of the rubber particles is unimportant. The rubber particles must cavitate before the stress state for brittle fracture of $\mathrm{PC}$ is reached in order to enhance the fracture toughness. We note that plastic dilatation of the voids in process zone II can occur and may absorb significant amounts of energy. However, this dilatation process, if it occurs, is distinct from the initial cavitation

Table 1 Width of process zone II in IM PC

\begin{tabular}{lc}
\hline Material & Width $(\mu \mathrm{m})$ \\
\hline PC only & 70 \\
PC + 5wt \% KM330 & 420 \\
PC + 10wt \% KM330 & 480 \\
PC + 15wt\% KM330 & 420 \\
PC + 5wt\% KM653 & 320 \\
PC + 10wt \% KM653 & 400 \\
PC + 15wt\% KM653 & 500
\end{tabular}

aidth of process zone II was determined as the widest region in the direction perpendicular to the crack growth direction 

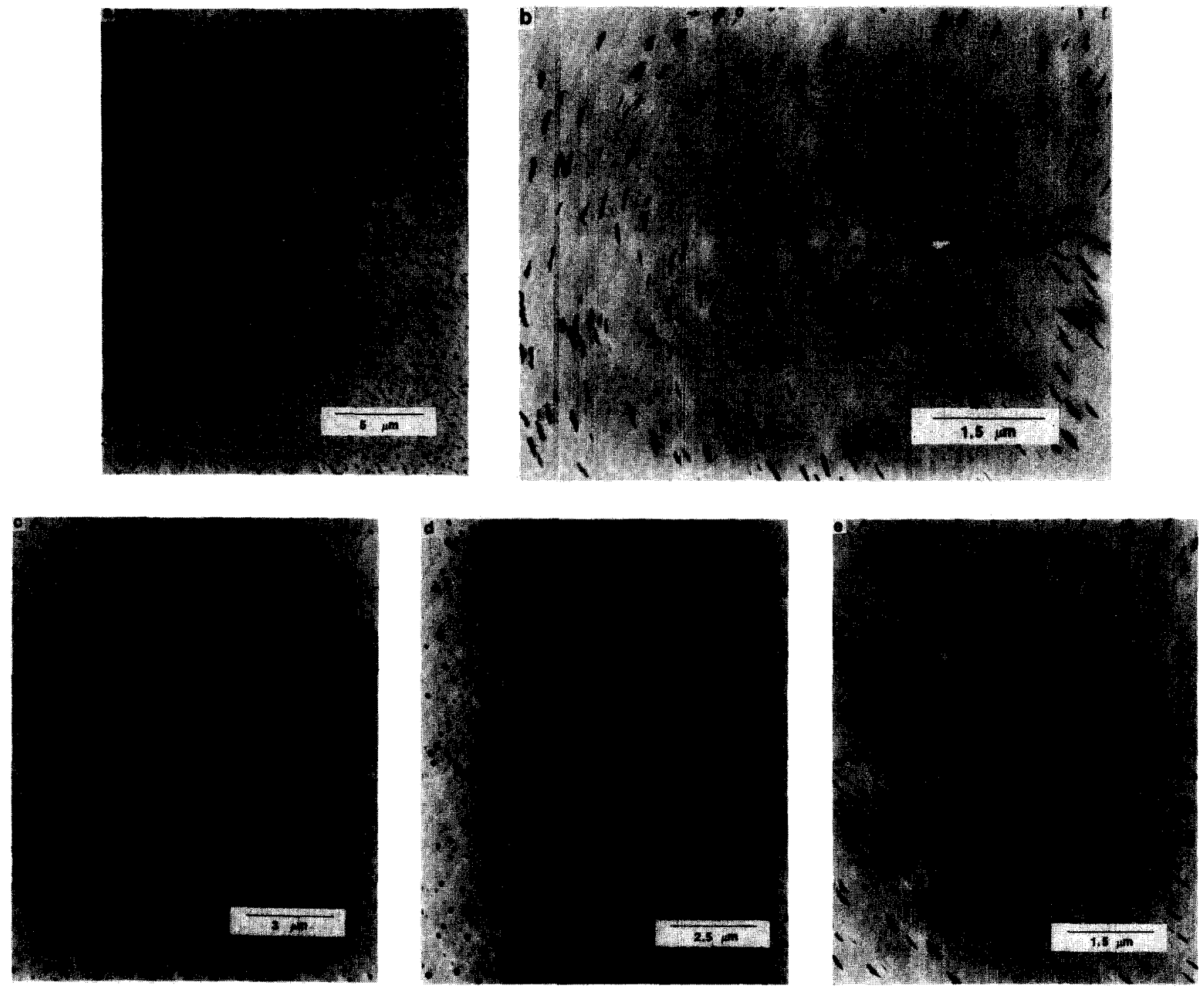

Figure 14 TEM micrographs of an $\mathrm{OsO}_{4}$ stained and then microtomed section of PC modified with $3.3 \mathrm{wt} \% \mathrm{KM} 653$ near the arrested crack tip. (a) Overview of the crack tip region: cavitation and shearing of the rubber particles are observed in front of the crack tip. (b) Higher magnification view of the crack tip. (c) Further ahead of the crack tip: the cavitation is accompanied by little distortion. (d) $160 \mu \mathrm{m}$ ahead of the crack tip: little deformation of any kind can be seen. (e) Subsurface zone behind the crack tip

process in zone $I$ in the sense that the dilatation of the matrix in zone I is not plastic.

Now that the sequence of events that occur during loading is clear and we have identified the differences in behaviour between the two IMs, we can explain some of the fracture surface features observed using the SEM.

The SEM photomicrograph of the fractured surface of PC modified with KM330 (Figure 6) shows larger voids and greater ligament tearing and stretching than observed in the KM653 modified series (Figure 7). The fracture toughness also indicates that at $15 \mathrm{wt} \%$ IM KM330 produces a lower fracture toughness than KM653. Though we are far from certain of the cause for this, these results could be explained by assuming that KM330 has lower cavitation resistance than KM653. If KM330 cavitates at a lower hydrostatic stress, the process zone I size would be larger. At the same external loads, the resulting voids in the KM330-modified material would grow to be large before failure occurs, thus producing thinner ligaments between the holes. When these ligaments finally tear, the crack tip and the plastic zone both advance. Thus, the earlier the ligaments tear, the smaller the lateral extent of the plastic zone becomes. As the concentration of the IM increases, the effects of the lower cavitation resistance of KM330 are compounded by the enhanced particle-particle or hole-hole interactions. Both effects reduce the size of the ligaments and thus their load carrying capacity, resulting in a lower fracture toughness for PC modified with $15 \mathrm{wt} \% \mathrm{KM} 330$. The reason why we do not observe greater differences in fracture toughness when using the two IMs is because at room temperature $\mathrm{PC}$ is very ductile and can be toughened easily. Perhaps if low temperature tests were conducted the effects of the different properties of the two IMs on fracture toughness could be observed.

The possibility that KM330 cavitates at a lower hydrostatic stress than KM653 (inferred from the results of the petrographic thin sections) raises questions regarding the usefulness of studying deformation mechanisms in ductile polymers through tensile dilatometry tests. The above results would indicate that the volume strain of PC modified with KM330 should be greater than PC modified with KM653. Tensile dilatometry results obtained in this study actually indicate that at the higher 

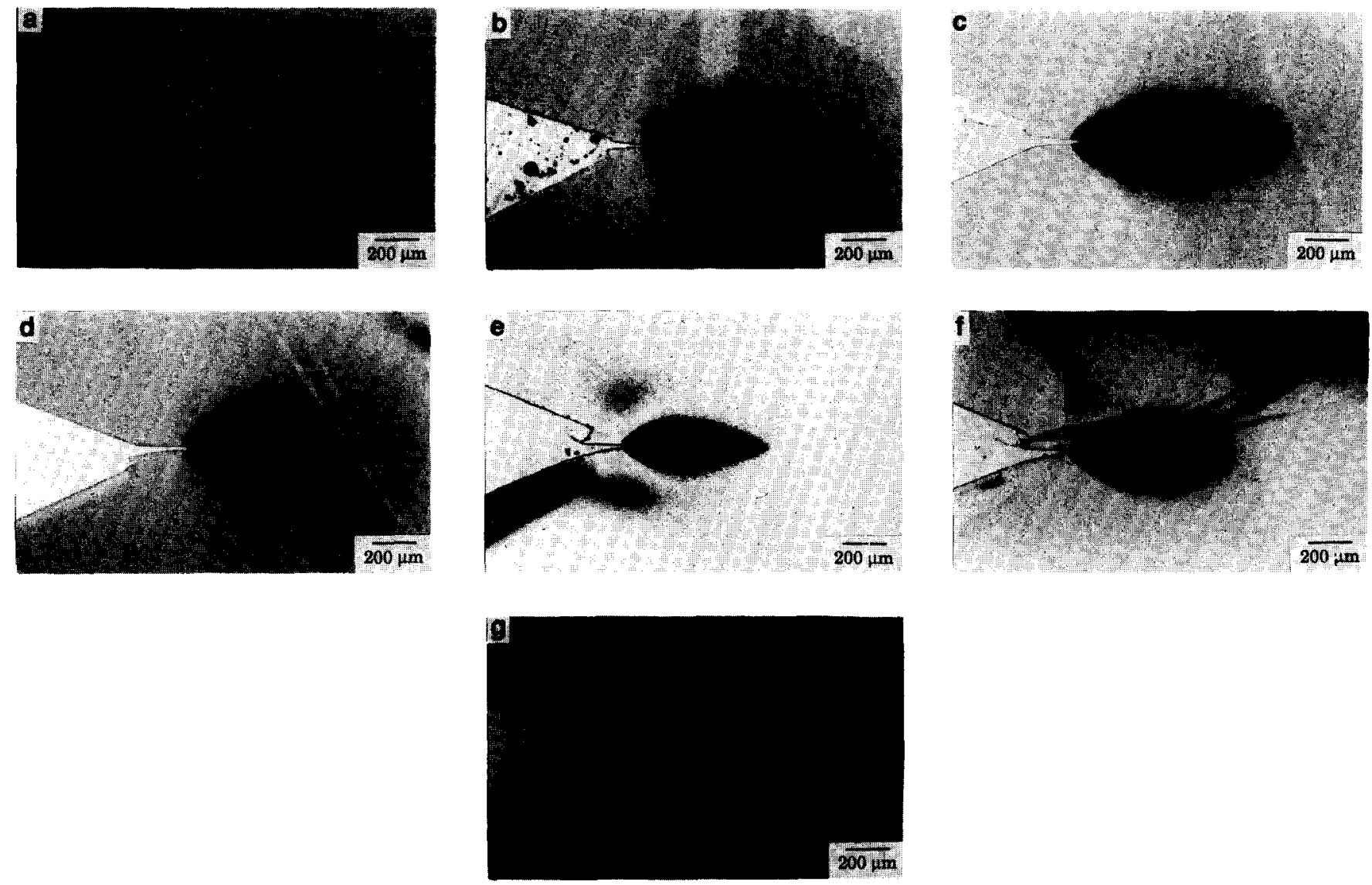

Figure 15 Petrographic thin sections ( $20 \mu \mathrm{m}$ thick) of the matured deformation zone in front of a crack tip taken perpendicular to the crack plane ( $J$ integral configuration). These samples were produced by loading each specimen to their respective $J_{\text {Ic }}$ value. (a) PC pure resin; (b) PC $+5 \mathrm{wt} \%$ KM330; (c) PC+10wt \% KM330; (d) PC+15wt\% KM330; (e) PC+5wt\% KM653; (f) PC+10wt\% KM653; (g) PC+15wt $\%$ KM653

strain rates the two IMs behave similarly and do not reflect the behaviour of the IMs during the fracture of a cracked specimen. These results illustrate the importance. of evaluating the deformation mechanisms by a variety of techniques. In certain situations tensile dilatometry may be useful; however, any conclusions reached through this technique must be viewed with caution if they are not supported by subsurface analysis performed at the crack tip.

Throughout this paper our discussion has focused on the formation and growth of cavities and shear yielding of the matrix as the primary energy dissipation mechanisms. However, other mechanisms also contribute to fracture toughness, e.g. crack tip shielding and crack tip blunting. Both of these mechanisms change the stress distribution in front of a crack tip and modify the stress intensity factor for crack propagation. The contribution of each of these mechanisms, as well as other possible mechanisms, to the increase in the fracture toughness of a material must also be evaluated in order to optimize them. We are currently attempting to model the toughening effects due to crack blunting and crack shielding ${ }^{31}$.

\section{CONCLUSIONS}

The fracture toughness of $\mathrm{PC}$ has been characterized by the $J$ integral technique. The critical $J$ value for crack initiation increases as the percentage IM by weight increases until the particle-particle interactions become significant. At this point, the $J_{\text {Ic }}$ values begin to decrease. When observing the deformation zone in front of an arrested crack using OM and TEM, we can confirm that cavitation of the rubber particles occurs first followed by enhanced shear yielding. The shape and size of the process zone which forms in front of the crack tip is governed by the mechanical properties of the rubber and the particular deviatoric and dilatational stress state at the crack tip.

\section{ACKNOWLEDGEMENTS}

We thank Dr Flexman of the Polymer Products Department of E.I. DuPont de Nemours and Company for compounding the materials and Ms Lisa Baumgarten and $\mathrm{Mr}$ E. I. Garcia-Meitin for performing the TEM analysis. This work was supported by a grant from the National Science Foundation (MRG grant DMR 8708405). Additional financial support from E.I. DuPont de Nemours and Company, B. F. Goodrich Company and Dow Chemical Co. is gratefully acknowledged. We also thank Professor C. B. Bucknall for commenting on the manuscript.

\section{REFERENCES}

1 Wu, S. Polymer 1985, 26, 1855

2 Sultan, J. N. and McGarry, F. J. Polym. Eng. Sci. 1973, 13(1), 29

3 Kinloch, A. J., Shaw, S. J., Tod, D. A. and Hunston, D. L. Polymer 1983, 24, 1341

4 Argon, A. S., Cohen, R. E., Gebizlioglu, O. and Schwier, C. in 'Advances in Polymer Science: Crazing in Polymers' (Ed. H. H. Kausch), Vol. 52/53, Springer, Berlin, 1983, p. 275

5 Borggreve, R. J. M., Gaymans, R. J. and Eichenwald, H. M. Polymer 1985, 30, 78 
6 Bascom, W. D., Ting, R. Y., Moulton, R. J., Riew, C. K. and Siebert, A. R. J. Mater. Sci. 1981, 16, 2657

7 Breuer, H., Haaf, F. and Stabenow, J. J. Macromol. Sci. Phys. 1977, B14(3), 387

8 Evans, A. G., Ahmad, Z. B., Gilbert, D. G. and Beaumont, P. W. R. Acta Metall. 1986, 34(1), 79

9 Yee, A. F. and Pearson, R. A. J. Mater. Sci. 1986, 21, 2462

10 Pearson, R. A. and Yee, A. F. J. Mater. Sci. 1986, 21, 2475

11 Bucknall, C. B. 'Toughened Plastics', Applied Science Publishers, London, 1977

12 Kunz-Douglas, S. C., Beaumount, S. and Ashby, M. F. J. Mater. Sci. $1980,15,1109$

13 Yee, A. F., Olszewski, W. V. and Miller, S. Adv. Chem. Ser. Am. Chem. Soc. 1976, 154, 97

14 Yee, A. F. J. Mater. Sci. 1977, 12, 757

15 Yee, A. F. and Maxwell, M. A. Polym. Eng. Sci. 1981, 21, 205

16 Yee, A. F. in 'Toughened Composites' (Ed. N. J. Johnston), American Society for Testing and Materials, Philadelphia, 1987, ASTM STP 937, p. 383

17 Kinloch, A. J. and Young, R. J. in 'Fracture Behavior of Polymers', Elsevier Applied Science, London, 1983, p. 421

18 Argon, A. S. in 'Advances in Fracture Research ICF7', Proc. 7th International Conference on Fracture (ICF7) (Eds K. Salama, K. Ravi-Chandar, D. M. R. Taplin and P. Rama Rao), Vol. 4, 1989, p. 2661

19 Dekkers, M. E. J., Hobbs, S. Y. and Watkins, V. H. J. Mater.
Sci. 1988, 23, 1225

20 Kinloch, A. J. and Hunston, D. L. J. Mater. Lett. 1986, 5, 909

21 Kyu, T. and Saldanha, J. M. J. Polym. Sci. Polym. Lett. 1988, 26, 33

22 Rice, J. R. J. Appl. Mech. 1968, 35, 379

23 Landes, J. D. and Begley, J. A. ASTM STP 560, 1974, p. 170

24 Standard Test Method for J1c, 'ASTM Standards', Designation: E813-81, 1981, p. 763

25 Sue, H. J. and Yee, A. F. J. Mater, Sci. 1989, 24, 1447

26 Yee, A. F., Pearson, R. A. and Sue, H. J. in 'Advances in Fracture Research ICF7', Proc. the 7th International Conference on Fracture (ICF7) (Eds K. Salama, K. Ravi-Chandar, D. M. R. Taplin and P. Rama Rao), Vol. 4, 1989, p. 2739

27 Sue, H. J., Pearson, R. A., Parker, D. S., Huang, J. and Yee, A. F. Polym. Prepr. 1988, 147

28 Holik, A. S., Kambour, R. P., Fink, D. G. and Hobbs, S. Y. in 'Proceedings of the Eleventh Annual Technical Meeting of the International Metallographic Society' (Eds 1. Le May, P. A. Fallon and J. L. McCall), Elsevier North Holland, 1979, p. 357

29 Hull, D. and Owen, T. W. J. Polym. Sci., Polym. Phys. Edn. 1973, 11, 2039

30 Sue, H. J. Mechanical modeling and experimental observations of toughened rigid-rigid polymer alloys, $P h . D$. Thesis, University of Michigan, 1988

31 Pan, J. and Yee, A. F. in preparation 